\title{
Treatment of Fracture Dislocation of the Femoral Head in a Resource Limited Country (Burundi)
}

\author{
Gilbert Ndayizeye1, Jean Claude Niyondiko', Sebastien Manirakiza², \\ Clovis Paulin Baramburiye ${ }^{3}$, Christopher Carter ${ }^{4}$
}

\author{
${ }^{1}$ Orthopedic Surgeon, University of Burundi, Kamenge Teaching Hospital, Bujumbura, Burundi \\ ${ }^{2}$ Radiology, University of Burundi, Kamenge Teaching Hospital, Bujumbura, Burundi \\ ${ }^{3}$ General Surgery, University of Burundi, Kamenge Teaching Hospital, Bujumbura, Burundi \\ ${ }^{4}$ Foundation for Development of Orthopaedics in Burundi, Bujumbura, Burundi \\ Email: ndayijapon@yahoo.fr
}

How to cite this paper: Ndayizeye, G. Niyondiko, J.C., Manirakiza, S., Baramburiye, C.P. and Carter, C. (2020) Treatment of Fracture Dislocation of the Femoral Head in a Resource Limited Country (Burundi). Open Journal of Orthopedics, 10, 384-394.

https://doi.org/10.4236/ojo.2020.1012036

Received: October 21, 2020

Accepted: December 15, 2020

Published: December 18, 2020

Copyright $\odot 2020$ by author(s) and Scientific Research Publishing Inc. This work is licensed under the Creative Commons Attribution International License (CC BY 4.0).

http://creativecommons.org/licenses/by/4.0/ (c) (i) Open Access

\begin{abstract}
Introduction: Fractures of the femoral head are rare injuries which generally follow a traumatic dislocation of the hip or in a poly-trauma scenario. A fracture dislocation of the femoral head is an orthopedic emergency. The most frequent complications after a fracture of the femoral head are osteonecrosis, post traumatic arthritis and heterotopic ossification. Objective: To focus on the therapeutic aspect of fracture-dislocations of femoral head and their short- and long-term prognoses. Materials and Methods: This is a prospective study conducted at Kamenge teaching hospital and Rohero Christian medical and surgical clinic from January 2013 to August 2020. All patients diagnosed with fracture-dislocations of the femoral head were included in this study. Results: Five patients were admitted for fracture dislocation of the femoral head. The mean age was 40.4 years and varied between 25 and 55 years. The dashboard injury was the most common mechanism and was found in four patients (80\%). A standard $\mathrm{x}$-ray was performed for the five patients as well as CT scans in two cases. All patients had posterior iliac dislocations with fractures of the femoral head classified as Pipkin I in three patients and Pipkin III in two patients. Closed reduction under general anesthesia within six hours was possible in one among the five patients and within 12 hours in two patients. These three cases were managed with open reduction and internal fixation (ORIF) via anterior approach with screw fixation of the femoral head fragment. In the two remaining patients reduction was not possible and for one of them there was a femoral neck fracture following closed manipulation, making the fracture Pipkin III. The two patients with Pipkin III injuries were managed with total hip replacement. With an average
\end{abstract}


follow up of five years, standard $\mathrm{x}$-rays of the three patients who had ORIF showed fracture union without avascular necrosis, posttraumatic arthritis or heterotopic ossification. The functional results for the five patients with an average follow up of four years were very good (3/5) and good (2/5). Conclusion: The diagnosis of fracture dislocations of the femoral head was based on clinical, radiographic and computed tomography criteria. Early reduction and internal fixation can restore the natural anatomy of the hip joint, especially in young adults with a good long-term prognosis. Sometimes total hip replacement is necessary for management of fracture dislocations of the femoral head.

\section{Keywords}

Fracture Dislocation, Femoral Head, Treatment, Prognosis

\section{Introduction}

Fractures of the femoral head are rare injuries which generally follow a traumatic dislocation of the hip or in a poly-trauma scenario [1] [2] [3]. Dislocation of the coxofemoral joint associated with a fracture of the femoral neck is rare and the mechanism is complex [4]. Fractures of the femoral head happen in only 6 to $28 \%$ of posterior dislocations of the hip [5].

A fracture dislocation of the femoral head is an orthopedic emergency. Reduction of the dislocation must be done under general anesthesia, preferably within the first six hours in order to minimize the risk of avascular necrosis of the femoral head [3]. In most cases, this includes fixation or excision of the fractured femoral head fragment. The most frequent complications after a fracture of the femoral head are osteonecrosis, post traumatic arthritis and heterotopic ossification [2]. Because this injury is so rare the treating surgeon has usually little or no prior experience and it is, therefore, relevant to focus on the therapeutic aspect of fracture dislocations of femoral head and their short- and long-term prognoses.

\section{Materials and Methods}

This is a prospective study conducted at Kamenge Teaching Hospital and Rohero Christian Medical and Surgical clinic from January, 2013 until August, 2020. Included in the study were all patients presenting with a fracture dislocation of the femoral head diagnosed by imaging studies available in Burundi (standard radiographs and/or CT scan). We evaluated the results of treatment of these injuries and their short-term and long-term prognoses. We recorded clinical, radiographic and functional criteria at an average follow up of four years. We evaluated pain and mobility according to the Merle d'Aubigné hip score (Table 1). The limits of our study are due to the small sample size because of the rarity of the injury. 
Table 1. The merle d'Aubigné hip score [6].

\begin{tabular}{|c|c|c|}
\hline Criteria & Assessment & Score (Points) \\
\hline \multirow{7}{*}{ Pain } & Intense and permanent & 0 \\
\hline & Severe even at night & 1 \\
\hline & Severe when walking, prevents any activity & 2 \\
\hline & & \\
\hline & Tolerable with limited activity & 3 \\
\hline & Mild when walking, disappearing at rest & 4 \\
\hline & Mild and inconsistent; normal activity & 5 \\
\hline \multirow{7}{*}{ Mobility } & Ankylosis with bad position of hip & 0 \\
\hline & No movement, pain or slight deformity & 1 \\
\hline & Flexion $<40^{\circ}$ & 2 \\
\hline & Flexion $40^{\circ}-59^{\circ}$ & 3 \\
\hline & Flexion $60^{\circ}-79^{\circ}$, foot can be reached & 4 \\
\hline & Flexion $80^{\circ}-90^{\circ}$, abduction of at least $15^{\circ}$ & 5 \\
\hline & Flexion exceeds $90^{\circ}$, abduction of $30^{\circ}$ & 6 \\
\hline \multirow{7}{*}{ Ability to walk } & None & 0 \\
\hline & Only with crutches & 1 \\
\hline & Only with canes & 2 \\
\hline & $\begin{array}{l}\text { With one cane, less than an hour, } \\
\text { very difficult without cane }\end{array}$ & 3 \\
\hline & $\begin{array}{l}\text { A long time with a cane, short time } \\
\text { without cane and limping }\end{array}$ & 4 \\
\hline & Without cane, slight limp & 5 \\
\hline & Normal & 6 \\
\hline \multirow{5}{*}{$\begin{array}{l}\text { Absolute results for } \\
\text { hip function }\end{array}$} & Very good & $11-12$ \\
\hline & Good & 10 \\
\hline & Medium & 9 \\
\hline & Fair & 8 \\
\hline & Poor & $\leq 7$ \\
\hline \multirow{5}{*}{ Relative results } & Very great improvement & $\geq 12$ \\
\hline & Great improvement & $7-11$ \\
\hline & & \\
\hline & Fair improvement & $3-6$ \\
\hline & Failure & $\leq 2$ \\
\hline
\end{tabular}


The Merle d'Aubigné hip score includes the parameters of pain, mobility, and ability to walk, each rated from 0 (worst condition) to 6 points (best condition). The sum of the scores of pain and mobility provides an absolute estimation of hip function.

The results are classified in two ways: absolute results (the evaluation of the functional value of the hip after the operation) and relative results (the appreciation of the difference between the preoperative and the postoperative functional states, in other words, the operative functional benefit gained by the patient).

\section{Results}

Five patients were admitted for fracture dislocation of the femoral head during the period of the study among whom two were females and three were males. The average age was 40.4 years and varied between 25 and 55 years. Road traffic accident was the commonest etiology and four patients (80\%) had a Dashboard injury. All patients had standard x-rays and two patients had CT scans. All of the five patients had a high posterior fracture dislocation with a femoral head fracture. Two patients had additional injuries, one had a head injury and one had a fracture of the contralateral distal femur. The fractures were classified as Pipkin I for three patients and Pipkin III for two patients. A closed reduction under general anesthesia was possible during the first six hours for one patient and within 12 hours for two patients. After the control x-ray and/or CT scan the three patients underwent ORIF via an anterior approach with screw fixation of the femoral head fragment (Figure 1, Figure 2). Trans tibial traction was set up for two weeks after the surgery and total weight bearing was allowed at two months postoperatively. In two patients closed reduction was not possible and one among the two had an association of a femoral neck fracture making the lesion Pipkin III. For these two patients, a total hip replacement (THR) was performed (Figures 3-5). Thromboembolic prophylaxis was systematically employed using low molecular weight heparin. All the patients had postoperative physiotherapy.

On a five years average follow-up, the fractures treated by ORIF healed without necrosis of the femoral head, osteoarthritis or heterotopic ossification (Table 2).

Table 2. Patient data.

\begin{tabular}{|c|c|c|c|c|c|c|c|}
\hline Age & Sex & Fracture type & $\begin{array}{l}\text { Delay to } \\
\text { reduction }\end{array}$ & Treatment & Follow-up & $\begin{array}{l}\text { Complications } \\
\text { (necrosis of femoral head, } \\
\text { osteoarthritis) }\end{array}$ & Results \\
\hline 25 & $\mathrm{~F}$ & Pipkin I & $>12 \mathrm{H}$ & ORIF & 6 years & No & Very good \\
\hline 37 & $\mathrm{~F}$ & Pipkin I & $>12 \mathrm{H}$ & ORIF & 5 years & No & Very good \\
\hline 55 & $\mathrm{M}$ & Pipkin I & $>6 \mathrm{H}$ & ORIF & 4 years & No & Good \\
\hline 48 & $\mathrm{M}$ & Pipkin III & Irreductibility & THR & 7 years & - & Good \\
\hline 37 & M & Pipkin III & Irreductibility & THR & 4 months & - & Very good \\
\hline
\end{tabular}




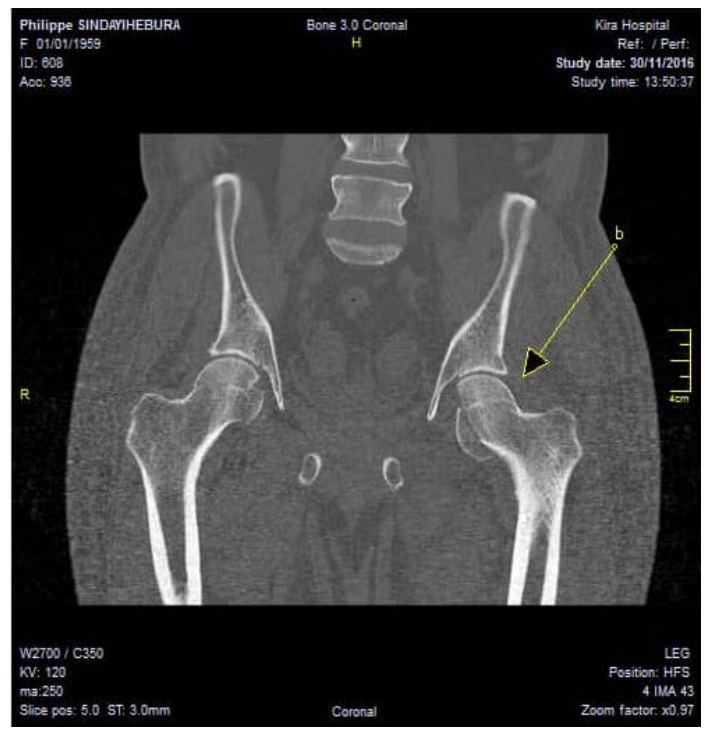

Figure 1. CT scan post closed reduction.

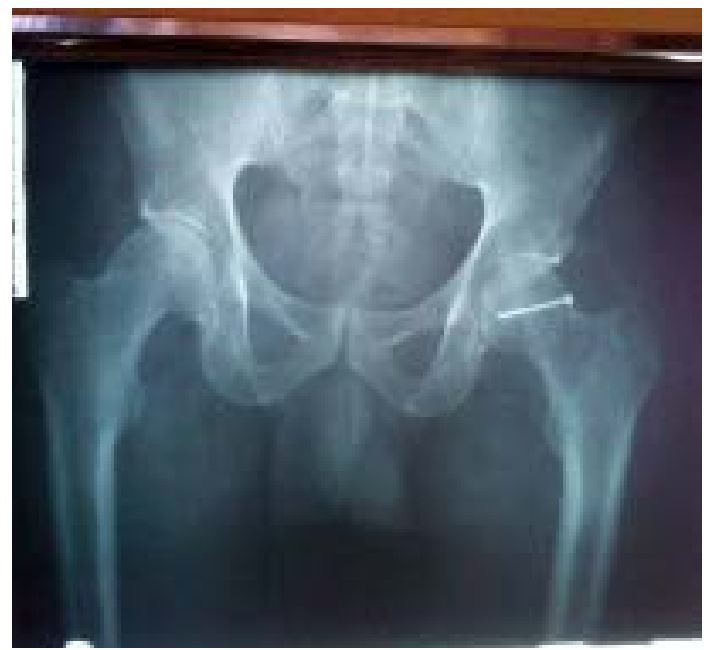

Figure 2. A 2 years anteroposterior x-ray after ORIF.

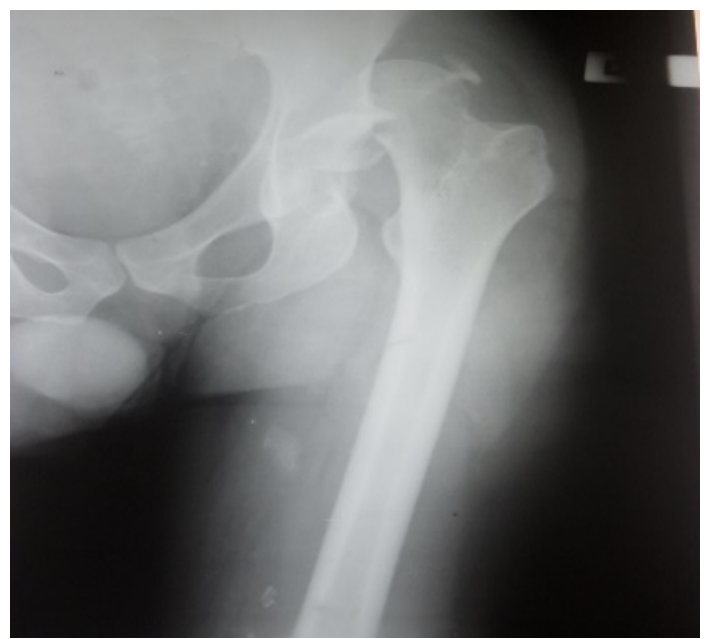

Figure 3. Anteroposterior x-ray Pipkin I. 


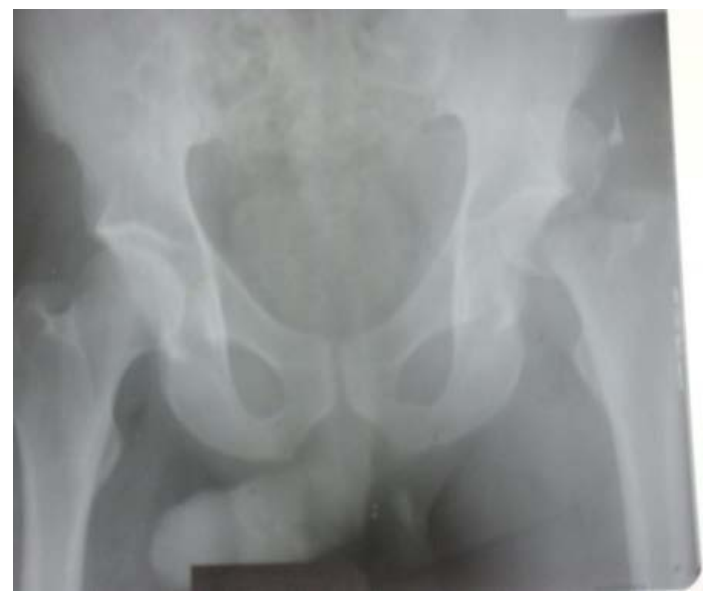

Figure 4. Post closed reduction anteroposterior x-ray Pipkin III.

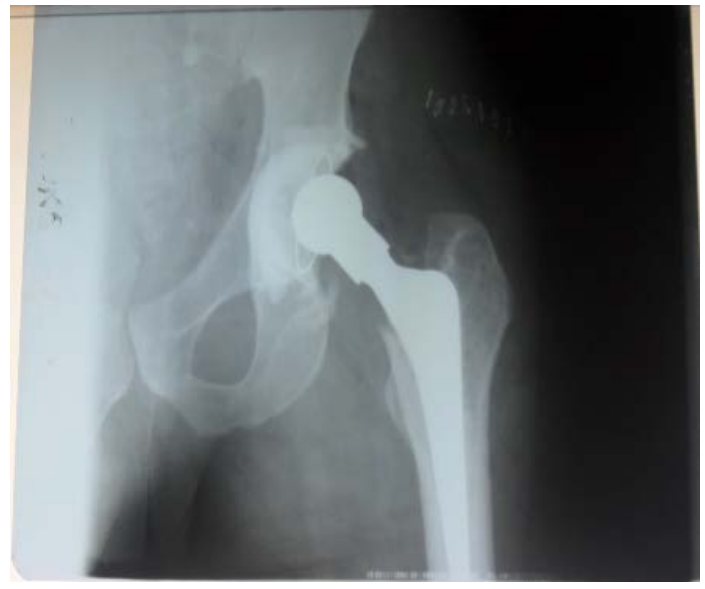

Figure 5. THR.

According to the Postel and Merle d'Aubigné hip score, the functional results at a four years average follow-up were very good (3/5) and good (2/5). Therefore, four patients resumed their daily routine life as before the injury.

\section{Discussion}

In this study, five patients were admitted for fracture dislocations of the femoral head and all of them had a high posterior dislocation. J. Toneti et al. [7] in a large retrospective series admitted between 1972 and 2008110 patients for fracture dislocation of the femoral head, the dislocations were posterior in 102 cases and anterior in eight cases. Posterior dislocation of the hip is more frequent [4]. All the patients presented with severe hip pain and deformity with abduction, internal rotation and shortening of the lower limb. One patient had signs of a sciatic nerve injury. Giannoudis et al. [8] reviewed the literature and found that the incidence of a sciatic nerve lesion associated with a femoral head fracture-dislocation was $3.95 \%$. Surgical exploration of the nerve is indicated if the sciatic nerve damage follows closed reduction [3]. According to Kenneth J. Koval and Philip J. Kragor [3], sciatic nerve damage occurs in $10 \%$ to $15 \%$ of hip 
dislocations.

In our study standard $\mathrm{x}$-rays were done for all patients and two among the five had a CT scan.

Vincenzo et al. [2] found that very small fragments of the head and free articular fragments can be very difficult to diagnose on standard $\mathrm{x}$-ray. This finding makes CT scan an essential diagnosis tool. McCarthy and Busconi [9] observed free fragments in the hip joint that were not diagnosed by conventional radiographs in $76 \%$ of traumatic hip dislocations undergoing arthroscopy.

Two patients in our series had associated injuries, one head injury and one fracture of the opposite distal femur. Suraci [10] reported that $95 \%$ of patients presenting traumatic dislocation of the hip following a road traffic accident had additional injuries necessitating in-hospital treatment. Knee injuries are particularly common. Tabuenca and Truan [11] reported that $25 \%$ of 187 patients with dislocation or fracture dislocation of the hip had associated serious injuries of the knee.

In our series, the fractures were classified Pipkin I for three patients and Pipkin III for two patients.

Pereira et al. [1], in a retrospective study of a database collected in a prospective manner in a trauma centre between 1987 in 2003 found 68 fractures of the femoral head, of which 35 (51\%) were classified Pipkin I, 22 (32\%) Pipkin II, 3 (4\%) Pipkin III and 8 (12\%) Pipkin IV.

In our series, a closed reduction under general anesthesia during the first six hours was performed in one patient and within 12 hours for two patients. In these three patients, a transtibial skeletal traction was placed and control radiographs were taken. Afterwards these three patients underwent surgery using an anterior approach and screw fixation of the femoral head. Tibial traction was continued for two weeks post operative.

The most important prognostic factor is probably the delay between injury and reduction of the dislocated hip [3]. Stewart and Milford [12] and Morton [13] reported excellent results if the hip was reduced in the 12 hours following injury. Brav [14] noted that reduction of the hip after 12 hours increased the percentage of unsatisfactory results from $22 \%$ to $52 \%$. Reigstad [15] found no cases of osteonecrosis or post-traumatic arthritis when simple dislocations were reduced during the first six hours. Hougaard and Thomsen [16] found increased incidence of osteonecrosis and arthritis if the delay in reduction was greater than six hours. While the majority of authors recommend urgent closed reduction, some recommend open reduction for all fracture dislocations in order to remove fragments from the joint and fix fragments if possible [3]. No study has demonstrated the superiority of open or closed reduction as long as the hip joint is congruent and clinically stable [3]. Indications for an open reduction of a dislocated hip include the inability to perform a closed reduction, post reduction articular incongruity and associated acetabular fracture causing instability of the hip [3].

In two of our patients, closed reduction was impossible and for one of these 
patients, a femoral neck fracture occurred and converted the injury to Pipkin III. These two patients then underwent a total hip replacement. In fact, these two patients were at high risk of avascular necrosis since their treatment was delayed beyond 12 hours. According to Li Wei [17], total hip arthroplasty is justified when the risk of necrosis is high.

In the series of J. Tonetti et al. [7], 32 cases had a nonsurgical treatment and 78 cases were treated surgically of which 51 were approached posteriorly, an anterior approach was used in 19 patients, 4 underwent a medial approach and 4 had an arthroscopic surgery. Surgery included ORIF of the femoral head in 30 cases and of the acetabulum in 16 cases, removal of fragments in 40 cases and total hip arthroplasty in five cases. The femoral head fractures occurred in the coronal plane and consequently fixation of the fragments was easier by using an anterior approach [3]. The Treatment of fractures of the femoral head depends on the site of the fracture and the presence of associated lesions. For Pipkin I, closed reduction is recommended if the fracture is non-displaced or minimally displaced (less than 1 to $2 \mathrm{~mm}$ ) and if the hip is stable. For displaced fractures, open reduction and internal fixation with small screws or absorbable pins is recommended via the anterior approach [3]. For young patients presenting with a Pipkin I or II fracture in which the hip is congruent and stable after reduction and the fragment is anterior or anterolateral it is preferable to use the SmithPeterson anterior approach or the Watson Jones anterolateral approach [2]. When the fragment is posterior or if there is an associated fracture of the posterior lip of the acetabulum (Pipkin IV) a posterior Kocher-Langenbeck approach is preferable. Pipkin I and II fractures have the same prognosis as a simple dislocation if reduction is performed in the first six hours [18]. Marecek and Routt [19] describe a percutaneous technique which enabled intra-articular bone fragments to be removed using a hook and fluoroscopy for guidance.

Thromboembolic prophylaxis was systematically administered to our five patients. Thromboembolism can happen after a traumatic hip dislocation so patients should receive adequate prophylaxis consisting of compression stockings, intermittent pneumatic compression and anticoagulation particularly if the patient must be in traction for a prolonged period [3].

In our series all patients had physiotherapy. Full weight bearing was authorized two months after the surgery for the patients who had ORIF and the day after surgery for the patients who had arthroplasty. Early mobilization is the goal after fixation of articular fractures; immobilization of joints can result in joint stiffness and adhesions leading to post-traumatic arthrosis so it must be avoided [3]. While certain authors have recommended a period of traction following reduction of hip dislocation until the initial pain has resolved, this has not been proven to be beneficial [3].

In fracture dislocation of the femoral head, it is often the associated injuries that determine the timing of patient mobilization, joint motion and weight bearing. With fractures of the posterior lip of the acetabulum, full weight-bearing is generally delayed for 8 to 12 weeks. Similar restrictions are usually recom- 
mended after fixation of a fracture of the head or neck of the femur [3]. Partial weight-bearing should start immediately with crutches or walker and should progress gradually until the fracture is healed and total weight bearing can be allowed [2].

At an average follow-up of five years, in our three patients who had osteosynthesis of the femoral head, radiographs showed fracture union without evidence of arthritis, necrosis or heterotopic ossification. Osteonecrosis can appear up to five years following the injury. Post traumatic osteoarthritis is the most frequent long-term complications of traumatic hip dislocation; the incidence is considerably higher when associated with fractures of the acetabulum or chondral fractures of the femoral head [3]. Giannoudis et al. [8] reported late complications including post-traumatic arthrosis (20\%), heterotopic ossification (16.8\%) and osteonecrosis (11.9\%). Vécsei V et al. [20] reported a series of 82 patients having suffered a dislocation of the hip. The treatment consisted of closed reduction under general anaesthesia in the first six hours followed by weight-bearing if tolerated after 14 days. 43 patients were available for follow-up ranging from six months to 19 years. Radiographic signs of arthritis were observed in 17 patients (40\%) but osteonecrosis was noted in only one hip.

Heterotopic ossification is frequent after posterior dislocation of the hip and might be related to muscle damage and haematoma formation. Surgery increases the incidence of heterotopic ossification. Prophylaxis for heterotopic ossification includes indomethacin for six weeks or low dose radiation [3].

In our series, functional results after an average follow-up of four years were excellent in one case, very good in two cases and good in two cases.

Marchetti et al. [21] reported a series of 33 patients who suffered a fracture dislocation of the femoral head and who were followed up for an average of 49 months. Globally the results were very good for $67 \%$ while $18 \%$ had good results and $15 \%$ bad results. No excellent results were reported. The Pipkin classification is a useful predictor of outcome; patients with Pipkin I or II injuries have statistically better results than those who are treated for Pipkin III or IV lesions.

Dreinhofer KE et al. [22] reported worse results in patients who had several serious injuries. Pape et al. [18] reported a series of 29 patients having suffered 31 traumatic dislocations and 13 patients were available for follow-up at 8 years. The clinical results were excellent in three, good in seven and acceptable in 4 hips. Five patients showed radiographic signs of premature hip degeneration and seven patients had osteonecrosis. The patients who had suffered fractures of the femoral head had worse results.

It is important to inform the patient and his family that complications and poor results can happen up to $50 \%$ of the time whatever the treatment [2].

\section{Conclusion}

The diagnosis of fracture dislocations of the femoral head depends on clinical, radiographic and computed tomography criteria. Early reduction and internal 
fixation can restore the normal anatomy of the hip especially in young adults thus ensuring a favourable prognosis. Sometimes immediate total hip replacement is necessary to treat these injuries.

\section{Conflicts of Interest}

The authors declare no conflicts of interest regarding the publication of this paper.

\section{References}

[1] Pereira, G., Droll, K., Meek, R., Blachut, P., Broekhuyse, H., Guy, P. and O'Brien, P. (2007) Outcomes of Femoral Head Fracture (Pipkin fractures). Injury Extra, 38, 151-152. https://doi.org/10.1016/j.injury.2006.12.134

[2] Giordano, V., Giordano, M., Glória, R.C., de Souza, F.S., di Tullio, P., Lages, M.M. and Koch, H.A. (2019) General Principles for Treatment of Femoral Head Fractures. Journal of Clinical Orthopaedics and Trauma, 10, 155-160. https://doi.org/10.1016/j.jcot.2017.07.013

[3] Koval, J.K. and Kregor, J.P. (2019) Hip Dislocation and Femoral Head Fractures. Surgery of the Hip, 48, 614-627.

[4] Niyondiko, J.C., Ndayizeye, G. and Nimubona, S. (2020) Analyse Physiopathologique d'une Lésion Traumatique de Hanche Rare. A Propos d'un cas. Journal Africain des Cas Cliniques et Revues, 4, 14-18.

[5] Brumback, R.J., Kenzora, J.E., Levitt, L.E., Burgess, A.R. and Poka, A. (1987) Fractures of the Femoral Head. Proceeding of the Hip Society, 18, 181-206.

[6] Merle d'Aubigné, R. and Postel, M. (1954) Functional Results of Hip Arthroplasty with Acrylic Prosthesis. The Journal of Bone and Joint Surgery, 36A, 451-475. https://doi.org/10.2106/00004623-195436030-00001

[7] Tonetti, J., Ruatti, S., Lafontan, V., Loubignac, F., Chiron, P., Sari-Ali, H. and Bonnevialle, P. (2010) Is Femoral Head Fracture-Dislocation Management Improvable? A Retrospective Study in 110 Cases. Orthopaedics \& Traumatology: Surgery \& Research, 96, 623-631. https://doi.org/10.1016/j.otsr.2010.03.020

[8] Giannoudis, P.V., Kontakis, G., Christoforakis, Z., Akula, M., Tosounidis, T. and Koutras, C. (2009) Management, Complications and Clinical Results of Femoral Head Fractures. Injury, 40, 1245-1251. https://doi.org/10.1016/j.injury.2009.10.024

[9] McCarthy, J.C. and Busconi, B. (1995) The Role of Hip Arthroscopy in the Diagnosis and Treatment of Hip Disease. Orthopedics, 18, 753-756.

[10] Suraci, A.J. (1986) Distribution and Severity of Injuries Associated with Hip Dislocations Secondary to Motor Vehicle Accidents. The Journal of Trauma: Injury, Infection, and Critical Care, 26, 458-460. https://doi.org/10.1097/00005373-198605000-00008

[11] Tabuenca, J. and Truan, J.R. (2000) Knee Injuries in Traumatic Hip Dislocation. Clinical Orthopaedics and Related Research, 377, 78-83. https://doi.org/10.1097/00003086-200008000-00011

[12] Stewart, M.J. and Milford, L.W. (1954) Fracture-Dislocation of the Hip: An End-Result Study. The Journal of Bone and Joint Surgery, 36, 315-342. https://doi.org/10.2106/00004623-195436020-00010

[13] Morton, K.S. (1959) Traumatic Dislocation of the Hip: A Follow-Up Study. Canadian Journal of Surgery, 3, 67-74. 
[14] Brav, EA. (1952) Traumatic Dislocation of the Hip: Army Experience and Results over a Twelve-Year Period. The Journal of Bone and Joint Surgery, 44, 1115-1134. https://doi.org/10.2106/00004623-196244060-00007

[15] Reigstad, A. (1980) Traumatic Dislocation of the Hip. The Journal of Trauma: Injury, Infection, and Critical Care, 20, 603-606. https://doi.org/10.1097/00005373-198007000-00010

[16] Hougaard, K. and Thomsen, PB. (1987) Coxarthrosis Following Traumatic Posterior Dislocation of the Hip. The Journal of Bone and Joint Surgery, 69, 679-683. https://doi.org/10.2106/00004623-198769050-00007

[17] Wei, L., Sun, J.-Y., Wang, Y. and Yang, X. (2011) Surgical Treatment and Prognosis of Acetabular Fractures Associated with Ipsilateral Femoral Neck Fractures. Orthopedics, 34, e1-e5. https://doi.org/10.3928/01477447-20110317-30

[18] Pape, H.C., Rice, J., Wolfram, K., Gänsslen, A., Pohlemann, T. and Krettek, C. (2000) Hip Dislocation in Patients with Multiple Injuries: A Follow Up Investigation. Clinical Orthopaedics and Related Research, 377, 99-105. https://doi.org/10.1097/00003086-200008000-00014

[19] Marecek, G.S. and Routt, M.L.C. (2014) Percutaneous Manipulation of Intra-Articular Debris After Fracture-Dislocation of the Femoral Head or Acetabulum. Orthopedics, 37, 603-606. https://doi.org/10.3928/014774447-20140825-04

[20] Vécsei, V., Schwendenwein, E. and Berger, G. (1997) Hip Dislocation without Bone Injuries. Der Orthopäde, 26, 317-326. https://doi.org/10.1007/PL00003387

[21] Marchetti, M.E., Steinberg, G.G. and Coumas, J.M. (1996) Intermediate-Term Experience of Pipkin Fracture-Dislocations of the Hip. Journal of Orthopaedic Trauma, 10, 455-461. https://doi.org/10.1097/00005131-199610000-00002

[22] Dreinhöfer, K.E., Schwarzkopf, S.R., Haas, N.P. and Tscherne, H. (1994) Isolated Traumatic Dislocation of the Hip: Long-Term Results in 50 Patients. The Journal of Bone and Joint Surgery, 76B, 6-12. https://doi.org/10.1302/0301-620X.76B1.8300683 